\title{
Enhancement of Natural GABA Production in Yogurt by Simple Carbohydrates and Metabolomics Profiling During Fermentation of Novel, Self-Cloned Lactobacillus Plantarum Taj-Apis362
}

\section{Farah Hussin}

Section of Food Engineering Technology, Malaysian Institute of Chemical and Bio-Engineering Technology, Universiti Kuala Lumpur

\section{Shyan Chay}

Department of Food Science, Faculty of Food Science and Technology, University Putra Malaysia Mohd Syahmi Abdul Ghani

Department of Food Science, Faculty of Food Science and Technology, University Putra Malaysia Anis Meor Hussin

Department of Food Science, Faculty of Food Science and Technology, University Putra Malaysia Wan Wan Ibadullah

Department of Food Science, Faculty of Food Science and Technology, University Putra Malaysia

\section{Belal Muhialdin}

Department of Food Science, Faculty of Food Science and Technology, University Putra Malaysia

Nazamid Saari ( $\nabla$ nazamid@upm.edu.my )

Department of Food Science, Faculty of Food Science and Technology, University Putra Malaysia

\section{Research Article}

Keywords: Fermentation, GABA, glucose, lactic acid bacteria, metabolomics, yogurt

Posted Date: December 22nd, 2020

DOl: https://doi.org/10.21203/rs.3.rs-129166/v1

License: (c) (i) This work is licensed under a Creative Commons Attribution 4.0 International License. Read Full License 


\section{Abstract}

This study aimed to enhance natural GABA production in yogurt by adding glucose $(2 \%, w / v)$ in the presence of low glutamate concentration $(11.5 \mathrm{mM} v s$. reported range of 32-507 mM) without the need of pyridoxal 5'-phosphate (PLP) cofactor, producing GABA at $58.56 \mathrm{mg} / 100 \mathrm{~g}$, significantly surpassing that of PLP $(48.01 \mathrm{mg} / 100 \mathrm{~g})$. Simulated gastrointestinal digestion showed a non-significant reduction in GABA content and probiotic viability, demonstrating resistance towards a high acidic environment $(\mathrm{pH}$ 1.2). Refrigerated storage up to 28 days revealed an improved GABA production of $83.65 \mathrm{mg} / 100 \mathrm{~g}$ compared to fresh GABA-rich yogurt prepared at day $1(59.00 \mathrm{mg} / 100 \mathrm{~g})$. Metabolomics profiling revealed different metabolite concentrations of amino acid, sugar and organic acid in GABA-rich and standard yogurt. The results successfully mitigate the over-use of glutamate substrate and omit the use of PLP cofactor during GABA enhancement in a fermented food system, offering an economical approach to produce a probiotic-rich dairy food with anti-hypertensive effect which is susceptible to manage stress and prevent cardiovascular disease.

\section{Introduction}

Yogurt is the fermented form of milk with a thick consistency and has been consumed since ancient time. In modern days, yogurt is appreciated for its high nutritional value and positive health benefits, owing to the probiotic effects from starter culture, i.e. lactic acid bacteria Streptococcus. thermophilus and Lactobacillus delbrueckii subsp. bulgaricus such as lactose digestion improvement ${ }^{1}$, diarrhea prevention ${ }^{2}$ and gut immune system stimulation ${ }^{3}$. Globally, the yogurt market has reached a value of approximately 85.54 billion USD in 2019, and is forecasted to increase to 106.6 billion USD by $2024^{4}$.

Gamma aminobutyric acid (GABA) is a non-protein amino acid which is widely distributed in animals, plants and microorganisms. In animals, it acts as the primary inhibitory neurotransmitter in central nervous system while in plants and microorganisms, it plays a key metabolic role in Krebs cycle ${ }^{5}$. Physiologically, GABA has significant functions such as stress reduction ${ }^{6}$, inhibition of cancer cell proliferation ${ }^{7}$, blood pressure reduction ${ }^{8}$ and prevention of diabetes ${ }^{9}$. The biosynthesis of GABA occurs mainly through the fermentative reaction from microorganisms such as yeast, fungi and bacteria. Most lactic acid bacteria (LAB), namely L. brevis, L. paracasei, L. plantarum, and Lactococcus lactis, have been reported to produce GABA through a-decarboxylation of glutamate substrate via enzymatic reaction of glutamate decarboxylase (GAD), a pyridoxal 5'-phosphate (PLP) dependent enzyme ${ }^{10}$. In this study, selfcloned and expressed L. plantarum Taj-Apis362 recombinant cells; UPMC90 (intracellular) and UPMC91 (extracellular) previously engineered by Tajabadi et al. ${ }^{11}$, were used to improve the GABA production in yogurt and can be considered safe since according to $90 / 219 /$ EEC $^{12}$, self-cloning is defined as reintroduction of DNA from a host that has been modified, or is closely related to the same species strain, and was excluded from the EU Directive on the contained use of genetically modified micro-organisms. Modified organism by self-cloning technique are now not viewed as genetic modified organism (GMO) and are regarded safe and suitable for food applications ${ }^{13}$. 
The need for high concentration of glutamate (32-507 mM) as well as the presence of PLP (18-200 $\mu \mathrm{M})$ have been identified as the major obstacles to produce GABA in a food system ${ }^{14}, 15$ as glutamate will produce salty/savoury taste at high concentration that is unfavourable for a yogurt product while PLP cofactor is a costly ingredient. However, due to the various health benefits of GABA, yogurt rich in GABA represents a value-added functional dairy product that can be conveniently consumed on a regular basis. To the best of our knowledge, there are only a few studies reported on the effect of sugar on enhancing GABA production in culture medium ${ }^{16,17}$ and no work has been reported on the effect of prebiotics in culture medium, let alone the effect of these simple carbohydrates in an actual food system. Therefore, the aims of this research were to study : (1) the effect of different types of carbohydrate (simple sugars and commercial prebiotics) on enhancing GABA production in yogurt, cultured by two novel, self-cloned LAB strains (L. plantarum Taj-Apis362, assigned as UPMC90 and UPMC91 by Institute of Bioscience, Universiti Putra Malaysia, Malaysia) in order to mitigate the over-use of glutamic acid and omit the need of PLP cofactor, (2) the stability of GABA-rich yogurt during gastrointestinal digestion and 28-days of refrigerated storage, and (3) the metabolomics profiling of the fermentation-derived biomolecules in yogurt using ${ }^{1} \mathrm{H}-\mathrm{NMR}$ technique.

\section{Results And Discussion}

\section{Effect of Simple Carbohydrates on GABA Production in Yogurt}

GABA production by microorganism is critically affected by factors including microbial genetic characteristics, culture condition (temperature, $\mathrm{pH}$, time) and medium condition (presence of glutamate and PLP). Most studies reported the requirement of glutamate at high concentrations (32-507 mM) and the presence of PLP (18-200 $\mu \mathrm{M})$ to achieve optimum GABA production in different food systems ${ }^{14}, 15$. In an attempt to mitigate glutamate and PLP usage during fermentation, current study is thus developed to improve the medium condition by incorporating different simple carbohydrates, in the form of simple sugars and prebiotics, to maximize GABA production. Our work identifies the lowest amount of glutamate $(11.5 \mathrm{mM})$ as the effective concentration to foster optimum GABA production, as compared to previous works which reported glutamate usage of $32 \mathrm{mM}$ in fermented palm date residue ${ }^{15}$ and $80 \mathrm{mM}$ in fermented milk ${ }^{18}$. This proves the efficient conversion of glutamate to GABA in yogurt fermented by UPMC90 and UPMC91 LAB strains under pre-defined optimum conditions ${ }^{19}$.

The effect of different simple sugars and prebiotics on GABA content and conversion rate is depicted in Fig. 1a. Of all six simple carbohydrates, simple sugars induce higher GABA production (42.83-58.56 $\mathrm{mg} / 100 \mathrm{~g}$ ) compared to prebiotics $(34.19-40.51 \mathrm{mg} / 100 \mathrm{~g})$. In particular, glucose significantly $(\mathrm{p}<0.05)$ induced the highest GABA production in yogurt $(58.56 \mathrm{mg} / 100 \mathrm{~g}$, conversion $=34.60 \%)$, favourably surpassing control sample added with PLP $(48.01 \mathrm{mg} / 100 \mathrm{~g}$, conversion $=28.38 \%)$, a cofactor well known to promote GABA biosynthesis. In terms of viable cell count, glucose again significantly showed the highest probiotic count ( $9.31 \mathrm{log} \mathrm{CFU} / \mathrm{g}$ ), followed by sucrose (9.06 log CFU/g) and fructose (8.98 log $\mathrm{CFU} / \mathrm{g}$ ), as depicted in Fig. 1b. The efficient utilization of glucose by LAB strains (both UPMC90 and 
UPMC91) and starter culture to produce the highest GABA and probiotic count is expected, as glucose is readily phosphorylated to glucose-6-phosphate in the glycolytic cycle of Embden-Meyerhof pathway and phosphoketolase pathway to achieve bacterial cell growth. In contrast, the other two simple sugars, namely sucrose and fructose, have to go through additional conversion steps in phosphoenolpyruvatedependent phosphotransferase system before being converted into pyruvate ${ }^{20}$, which then either splits into the GABA-shunt pathway to form GABA or continues to be decarboxylated through glycolytic pathway to generate ATP, NADH and NADPH for cell growth ${ }^{21}$. The straightforward metabolism pathway of glucose explains the rapid bacterial growth when the sugar is present, allowing the growth cycle to reach an exponential phase in a shorter time compared to other simple carbohydrates. The accumulation of active bacterial cell then contributes towards higher secretion of GAD, thus higher enzymatic activity to convert glutamate into GABA. This observation establishes a positive correlation between viable cell count and GABA production during fermentation, i.e. higher viable count is associated with higher GABA formation.

An interesting observation was made on the yogurt containing prebiotics (inulin, FOS, GOS), of which they recorded GABA contents and viable cell counts that were substantially lower than simple sugars. This indicates the poor utilization of prebiotics during bacterial metabolic activity as a result of high degree of polymerization (DP) ranging from 2 to 65 in the prebiotics ${ }^{22}$. Similarly, Hernandez-Hernandez et al. ${ }^{23}$ reported lower growth of L. casei ATCC11578 and L. delbrueckii subsp. lactis ATCC4797 strains when GOS is present instead of glucose and lactulose (a synthetic disaccharide). Rayes ${ }^{24}$ also described that carbohydrates with high DP were poor substrates for bifidobacteria. This is because prebiotics with higher DP requires cleavage into monosaccharides with lower DP by extracellular bacterial enzymes prior to transportation into the cells for growth ${ }^{25}$.

Among three tested prebiotics, inulin produced significantly higher GABA than FOS and GOS, but lower probiotic growth compared to FOS (Fig. 1a and 1b), suggesting that LAB strains of UPMC90 and UPMC91, with high GAD enzyme activity, prefer to metabolize inulin over FOS. In accordance to our results, Choudhary et al. ${ }^{26}$ also showed that inulin was fermented at a higher rate than FOS by $L$. paracasei CD4 in soymilk. According to Sarbini \& Rastall ${ }^{27}$, there are specific transport systems in LAB for trisaccharides and tetrasaccharides, indicating the occurrence of different metabolic capacity based on type of substrate used. In addition, each strain of LAB have their preferred choice of prebiotics to prioritize as substrate during fermentation, depending on their respective genetic characteristics ${ }^{28}$. These findings explain the preferred utilization of inulin over FOS by the UPMC90 and UPMC91 strains used in current study. On the other hand, the high viable cell count in FOS compared to inulin is mostly contributed by the abundance of starter culture, i.e. S. thermophilus and L. delbrueckii ssp. bulgaricus, present in the sample.

For PLP sample $(50 \mu \mathrm{M}$, positive control), GABA production is enhanced $(48.01 \mathrm{mg} / 100 \mathrm{~g}$, conversion $=$ $28.38 \%$ ) compared to yogurt without addition of any simple carbohydrates (negative control, 29.95 $\mathrm{mg} / 100 \mathrm{~g}$, conversion $=17.71 \%$ ). This result demonstrated a higher GABA conversion compared to that reported by Yi \& Chui ${ }^{29}$, who used $8.09 \mathrm{mM}$ of PLP and $134 \mathrm{mM}$ of monosodium glutamate in adzuki 
bean milk fermented by L. rhamnosus GG. PLP sample also showed the lowest viable cell count (log 6.76 $\mathrm{CFU} / \mathrm{g}$ ) similar to negative control, indicating no significant effect on promoting bacterial cell growth compared to simple carbohydrates. This is supported by previous study by Li et al. ${ }^{30}$ who reported that PLP did not affect the growth of $L$. brevis NCL912. The presence of PLP in yogurt is concluded to enhance GABA production but has no effect in promoting the growth of L. plantarum Taj-Apis362 strain UPMC90 and UPMC91. Among all tested simple carbohydrates, glucose displayed the highest substrate efficiency for bacterial metabolism, rapidly promoting cell growth which enhanced the conversion of glutamate into GABA during yogurt fermentation, thus was selected for further studies as detailed below.

\section{Simulated Digestion Study on GABA-rich Yogurt}

In vitro gastrointestinal digestion is regarded as an effective and valid strategy to simulate digestive activities in the human gastrointestinal tract. Various mechanical, chemical and enzymatic actions occur within the human digestive tract to degrade food matrices, releasing nutrients that are readily absorbed by the body. In this study, simulation was performed at $\mathrm{pH} 1.2$ for the first $2 \mathrm{~h}$ to mimic stomach digestion, followed by increasing the $\mathrm{pH}$ to 6.8 for the next $4 \mathrm{~h}$ to mimic intestinal digestion. The results of GABA stability and the survival of probiotic cultures are shown in Fig. 2, as GABA content and viable cell count, respectively. No significant reduction of GABA was observed after $6 \mathrm{~h}$ of digestion. While gastrointestinal enzymes such as pancreatin and pepsin are available to perform hydrolysis in the simulated system, GABA is not digested because it is a non-protein amino acid, i.e. not a substrate for these enzymes. Instead, the structural integrity and stability of GABA is maintained through resistance towards acidic $\mathrm{pH}$. Similarly, a study by Le et al. ${ }^{31}$ revealed no significant reduction on GABA content in germinated soymilk after $2 \mathrm{~h}$ of simulated digestion at $37^{\circ} \mathrm{C}$.

In contrast, a slow reduction in probiotic viability was detected over the course of hydrolysis, with descending values from $9.31 \mathrm{log} \mathrm{CFU} / \mathrm{g}$ at $0 \mathrm{~h}$ to $8.49 \mathrm{log} \mathrm{CFU} / \mathrm{g}$ at the end of $6 \mathrm{~h}$ digestion. A similar reduction was reported for $L$. acidophilus La- 5 in fermented soy product ${ }^{32}$ and $B$. animalis subsp. lactis in goat's milk ice cream ${ }^{33}$ under the same assay conditions. Probiotics is only deemed beneficial and useful when they could tolerate harsh acidic condition in stomach and withstand further digestion in small intestine to reach large intestine in viable form, restoring gut microbial balance. While viable count reduced significantly after digestion in current study, the viability is not totally destroyed, but rather, maintained at $8.49 \mathrm{log} \mathrm{CFU} / \mathrm{g}$ at the end of digestion. This is very likely due to a complementary effect from the acid-resistance nature of bacteria and $\mathrm{H}^{+}$ion dependent GABA production cycle. Coherently, Sanchart et al. ${ }^{34}$ reported the survival of $\mathrm{LAB}$ at $\mathrm{pH}<2.5$ for at least $2 \mathrm{~h}$, while Wang et al. ${ }^{35}$ reported that GABA production involves the consumption of $\mathrm{H}^{+}$ion from extracellular environment, making it less acidic and favourable for probiotic survival. This study highlights the stability of UPMC90 and UPMC91 LAB strains and starter culture to maintain viable cell count after simulated digestion.

\section{8-days Storage Stability Study}

\section{GABA content, viable cell count and pH}


The GABA content and probiotic viability during storage are vital to ensure good bio-functionalities and health benefits to be delivered to consumers without jeopardising its organoleptic property (in terms of sourness measured as $\mathrm{pH})$. The effect of 28 -days refrigerated storage $\left(2-4^{\circ} \mathrm{C}\right)$ on GABA content, viable cell count and $\mathrm{pH}$ of GABA-rich yogurt are illustrated in Fig. 3. A significant increase in GABA content was observed over 28-days storage compared to freshly-fermented yogurt on day 1 (59.00 mg/100g). GABA content reached the maximum of $113.95 \mathrm{mg} / 100 \mathrm{~g}$ on day 21 and decreased to $83.65 \mathrm{mg} / 100 \mathrm{~g}$ on day 28. Despite of this reduction, GABA content was still higher than the initial value, indicating that refrigerated storage up to 28 days is acceptable, but storage of 21 days is the optimum. The overall improvement of GABA content over 28 days storage period reflects the continuous formation of GABA by the GABA-producing LAB strains of UPMC90 and UPMC91 as well as starter culture throughout the study period. The increasing GABA content during storage is in agreement with previous finding ${ }^{36}$, whereby GABA increased from $5.71 \mathrm{mg} / 100 \mathrm{~g}$ (day 1 ) to $10.33 \mathrm{mg} / 100 \mathrm{~g}$ (day 14) during refrigerated storage of yogurt cultured with starter culture and GABA-producing strains of L. cremoris and L. lactis 0-114, L. helveticus Lh-B 02 and L. rhamnosus B-1445.

The viable cell count of GABA-rich yogurt was initially recorded at $9.68 \log$ CFU/g on day 1 and peaked at $10.23 \log \mathrm{CFU} / \mathrm{g}$ on day 14, followed by a sharp reduction to 9.17 and further to $9.06 \mathrm{log} \mathrm{CFU} / \mathrm{g}$ on day 21 and 28 , respectively. While the viability reduced over time, it is still in accordance to the minimum standard count of $6.00 \mathrm{log} \mathrm{CFU} / \mathrm{g}$ as required for probiotic food recognition ${ }^{37}$, thus fostering the potential of GABA-rich yogurt as a probiotic food during 28 days of storage. An interesting observation was made on the reduced viable cell count on day 21 which recorded the highest GABA content. This is due to the fact that GABA is accumulated progressively over time and is rarely converted into other final products by microbial reaction, as GABA is not a preferred substrate compared to other sugars in the fermentation medium, thus allowing the cumulative detection. In contrast, the reduced GABA content at the end of storage (day 28) was possibly due to structural instability in GABA which led to molecular selfdegradation, along with minimal occurrence of microbial/enzymatic reactions. Since 28 days of storage draws early sign of GABA instability, extending storage time longer than 28 days is not recommended. In terms of $\mathrm{pH}$, a significant reduction was observed from $\mathrm{pH} 3.99$ to 3.88 in GABA-rich yogurt, due to the production of lactic acid by the viable cells via lactose fermentation in the milk during refrigerated storage $^{38}$. These $\mathrm{pH}$ range falls within the acceptable limit of $\mathrm{pH}$ 3.7-4.6 for commercial yogurt thus complying with the product specification requirement.

In standard yogurt, GABA was produced at a minimal level by starter culture (a mixture of $S$. thermophilus and $L$. delbrueckii ssp. bulgaricus), recording values from $9.02 \mathrm{mg} / 100 \mathrm{~g}$ (day 1 ) to $17.16 \mathrm{mg} / 100 \mathrm{~g}$ (day 28) that were significantly lower than that of GABA-rich yogurt. While the GABA-producing ability of these two strains has been acknowledged ${ }^{39}$, it depicted a low conversion rate. Coherently, Watanabe et al. ${ }^{40}$ observed a poor GABA production (less than $5 \mathrm{mM}$ ) after $48 \mathrm{~h}$ of milk fermentation by the said starter culture. Therefore, GABA-rich yogurt was successfully proven to contain higher amount of GABA compared to standard yogurt at all times, during 28 days of storage at refrigerated temperature.

\section{Water holding capacity and syneresis}


Water holding capacity $(\mathrm{WHC})$ and syneresis directly reflect the coagulum strength of yogurt as a semisolid, gel-like food product and is related to the textural and sensorial properties (mouthfeel, eating experience) of a product ${ }^{41}$. Syneresis, a common phenomenon in yogurt, is considered unfavourable to consumers owing to the presence of exudate/fluid release from the food matrix. As shown in Fig. $4 \mathrm{a}$, the WHC of GABA-rich and standard yogurt recorded no significant changes over 28 days of storage, except for increment on day 7 , indicating high stability of yogurt samples over time. The result from syneresis study (Fig. 4b) showed GABA-rich yogurt exhibiting a minor decrease in syneresis values (11.70-15.03\%) compared to standard yogurt (20.79-21.63\%) during storage. Low syneresis values are mostly contributed by the acidic environment in both samples helps to enhance the gel network to resist syneresis during storage ${ }^{42}$. According to Lobato-Calleros et al. ${ }^{43}$ and Nguyen et al. ${ }^{44}$, the increasing WHC and reducing syneresis were resulted from the effective water molecule entrapment in the protein network structure. However, the effect of glucose addition on WHC and syneresis is not statistically different between GABA-rich yogurt and standard yogurt at the day of storage with $p$-value $>0.05$.

\section{${ }^{1} \mathrm{H}-\mathrm{NMR}$ Metabolomics Analysis}

From a molecular point of view, yogurt comprises of hundreds of biomolecules including proteins, lipids, sugars, amino acids, organic acids, fatty acids, minerals and volatile aroma compounds that contribute to the overall flavour and taste profile. In this study, both GABA-rich and standard yogurt were freeze-dried prior to nuclear magnetic resonance (NMR) spectroscopy analysis to prevent signal interference from water molecules ${ }^{45}$. It is known that each microorganism induces metabolite changes via different metabolic pathway during fermentation of food ${ }^{46}$. Therefore in this study, a metabolomics approach based on ${ }^{1} \mathrm{H}$-NMR technique was used to compare the major metabolite profile between freeze-dried GABA-rich yogurt (GY) and freeze-dried standard yogurt (SY), since both samples were fermented from milk by different microorganisms, of which SY contains only starter culture of $S$. thermophilus and $L$. delbrueckii ssp. bulgaricus while GY contains additional GABA-producing LAB strains of UPMC 90 and UPMC91.

Fig. 5 depicts the ${ }^{1} \mathrm{H}-\mathrm{NMR}$ spectra for a mixture of metabolites, consisting of amino acid, sugar and organic acid (lactic acid). A total of 16 and 13 compounds were detected in GY and SY, respectively. The metabolite profiles, observed as different spectrum pattern between GY and SY, is possibly due to the strain-specific metabolic activities of GABA-producing LAB strains (UPMC90 and UPMC91). Similarly, a previous study reported that the free phenolic content varied during fermentation of whole-grain barley when different species of lactobacillus were used ${ }^{47}$. Table 1 tabulates the amino acid, sugar and organic acid content of GY and SY. Briefly, GY comprised of 7 amino acids including GABA, glutamine, alanine, histidine, proline, cysteine and valine while SY comprised of only 4 amino acids including GABA, alanine, histidine and choline. In cases where amino acid was present in both samples, GY showed higher concentration than SY except for alanine. Similarly, GY demonstrated higher GABA content (97.65 $\mathrm{mg} / 100 \mathrm{~g})$ than $S Y(25.10 \mathrm{mg} / 100 \mathrm{~g})$. This portrays the successful role of glucose added extrinsically into the fermentation medium to enhance natural GABA production by UPMC90 and UPMC91 LAB strains. 
Also, the slight GABA value in SY indicated that GABA was produced naturally by starter culture without the presence of GABA-producing strains.

In terms of sugar, 7 types of sugar (glucose, lactose, lactulose, trehalose, arabinose, galactose and Nacetylglucosamine) were identified from both GY and SY samples. Higher amounts of glucose (311.85 $\mathrm{mg} / 100 \mathrm{~g})$, trehalose $(1174.00 \mathrm{mg} / 100 \mathrm{~g})$ and galactose $(549.48 \mathrm{mg} / 100 \mathrm{~g})$ were observed in $\mathrm{GY}$ compared to SY. The high concentration of glucose was due to the external addition of this sugar into the fermentation medium as GABA enhancer, thus detected at higher value than SY. As for galactose, it was excreted into the medium when the microorganisms (starter culture and GABA-producing LAB strains) consumed the glucose moiety of lactose in the milk ${ }^{48}$, leaving behind galactose residue. The increased level of galactose in GY indicated high consumption rate of lactose as the preferred substrate among starter culture co-inoculated with UPMC90 and UPMC91 LAB strains. Similar to our findings, higher galactose content was obtained when co-culturing L. plantarum WCFS1 with $S$. thermophilus and $L$. delbrueckii ssp. Bulgaricus compared to that without L. plantarum WCFS $1^{49}$. Lower amount of lactose correlates to the lower amount of lactic acid in GY. This could be explained by the heterofermentative metabolism of UPMC90 and UPMC91 strains in GY, which favour lactose utilisation for energy production while generating metabolites other than lactic acid, thus lowering the amount of lactic acid.

In contrast, starter culture (S. thermophilus and L. delbrueckii ssp. bulgaricus) in SY produced higher lactic acid due to homofermentative metabolism that generates lactic acid as the main end-product during fermentation ${ }^{50}$. While yogurt is widely recognised to be suitable for lactose-intolerant individuals, the significantly lower amount of lactose in GY (346.41 mg/100g), as compared to SY ( 1025.00 $\mathrm{mg} / 100 \mathrm{~g}$ ), provides additional benefit to patients suffering from severe lactose intolerant symptoms. In short, the metabolites were produced as a result of major structural alteration of milk components through two biochemical pathways from the microorganisms: (i) glycolysis where carbohydrate was converted into lactic acid or other metabolites, and (ii) proteolysis where casein was hydrolysed into peptide or free amino acid $^{51}$.

\section{Conclusion}

Current study represents a pioneer that reports the effect of simple sugars and prebiotics on enhancing natural GABA production in a food system (yogurt) along with metabolomics profiling of the generated biomolecules. Simple sugars induced higher GABA production compared to prebiotics through natural fermentation by two novel, self-cloned L. plantarum Taj-Apis362 strains (UPMC 90 and UPMC91) in the yogurt. In particular, glucose served as a superior choice over PLP by successfully enhanced GABA production at a very low concentration of glutamate substrate $(11.5 \mathrm{mM})$. Simulated gastrointestinal study and storage study coherently revealed good stability of GABA and viable cell count under gastrointestinal condition as well as refrigerated storage up to 28 days, meeting the minimum requirement of $6.00 \mathrm{log} \mathrm{CFU} / \mathrm{g}$ for recognition as probiotic food. The addition of glucose also does not affect the water holding capacity and syneresis values of GABA-rich yogurt as there was no significant 
difference detected when compared with standard yogurt. ${ }^{1} \mathrm{H}-\mathrm{NMR}$ analysis revealed different metabolomics profile of GABA-rich yogurt and standard yogurt, detecting 16 and 13 compounds (amino acid, sugar and organic acid), respectively. This study successfully mitigates the over-use of glutamate substrate and omits the use of expensive PLP cofactor in the production of GABA-rich yogurt, offering an economical approach to produce a probiotic-rich, functional dairy food with prospective stress management and cardiovascular disease prevention properties.

\section{Materials And Methods}

\section{Materials}

Non-fat skim milk powder (Sunlac ${ }^{\circledR}$ brand) and pasteurized fresh milk (Goodday ${ }^{\circledR}$ brand) were locally purchased. Food grade commercial prebiotics (with 90-95\% purity), inulin and galactooligosaccharides (GOS) were purchased from CK Chemical Sdn Bhd and fructooligosaccharides (FOS) was purchased from Greenfinite Sdn Bhd. MRS agar and MRS broth were obtained from HiMedia Laboratories Pvt. Ltd. (Mumbai, India). Glutamate, GABA standard and triethylamine were obtained from Merck KGaA (Darmstadt, Germany). Methanol- $\mathrm{d}_{4}$, deuterium oxide $\left(\mathrm{D}_{2} \mathrm{O}\right)$ and sodium deuteroxide $(\mathrm{NaOD})$ used for NMR analysis were purchased from Cambridge Isotope Laboratories, Inc. (Tewksbury, MA, USA). All other chemicals used were of analytical or HPLC grade.

\section{Preparation of Starter Culture and GABA-producing LAB strains}

Two L. plantarum Taj-Apis362 strains possessing high intracellular GAD activity (UPMC90) and high extracellular GAD activity (UPMC91) were obtained from the culture collection of Institute of Bioscience, Universiti Putra Malaysia and routinely stored in sterile MRS broth at $-80^{\circ} \mathrm{C}$ as stock culture. These strains were characterized from previous work, where the wild-type L. plantarum Taj-Apis362 was previously isolated from the stomach of honeybee Apis dorsata, and used as a host for GAD gene overexpression to produce UPMC90 and UPMC91 strains ${ }^{11}$. All procedures involving the use of $L$. plantarum Taj-Apis strains received approval from National Board of Biosafety, Ministry of Natural Resources and Environment, Malaysia (approval no. JBK [S]-602-1/2/207). Commercial starter culture (Lactina ${ }^{\circledR}$ brand) containing S. thermophilus and L. delbrueckii ssp. bulgaricus was obtained from YogurtBio (Sofia, Bulgaria). Reconstituted skim milk was prepared by mixing commercial pasteurized fresh milk and skimmed milk powder to reach $16 \%$ of nonfat dry matter. It was then submitted to thermal treatment at $80-85^{\circ} \mathrm{C}$ for $30 \mathrm{~min}^{44}$, cooled to $4^{\circ} \mathrm{C}$ in an iced bath, poured into $250-\mathrm{mL}$ screw capped Schott bottles and stored at $4^{\circ} \mathrm{C}$ for $24 \mathrm{~h}$ before used. At the beginning of each fermentation cycle, i.e.

production of new batch of yogurt sample, starter culture and LAB strains were prepared freshly from the stock. Starter culture was inoculated in a sterilised reconstituted skim milk prepared previously and incubated at $42^{\circ} \mathrm{C}$ for about $6 \mathrm{~h}$ until reaching $\mathrm{pH}$ 4.5-4.6. On the other hand, LAB strains were streaked for single colony isolation on MRS agar, then transferred to $10 \mathrm{~mL}$ MRS broth, incubated for $18 \mathrm{~h}$ at $37^{\circ} \mathrm{C}$ to allow cell growth, and further transferred to sterilised reconstituted skim milk for sub-culturing for 22$24 \mathrm{~h}$. At the end of incubation, the coagulated milk was employed as inoculum for yogurt production. 


\section{Addition of Sugars and Prebiotics into Yogurt}

Eight samples of yogurt were prepared: negative control (yogurt with glutamate only), positive control (yogurt with glutamate $+50 \mu \mathrm{M}$ of PLP cofactor), and yogurt with glutamate $+2 \%(\mathrm{w} / \mathrm{v})$ of glucose, sucrose, fructose, inulin, FOS and GOS, respectively. Briefly, the yogurt samples were prepared by coinoculating starter culture and GABA-producing LAB strains (having viable count of $10^{6} \mathrm{CFU} / \mathrm{g}$ ) simultaneously at a ratio of 2:1 w/w, into fresh sterilised reconstituted skim milk. A total of $11.5 \mathrm{mM}$ of glutamate was added and fermentation was allowed for $7.25 \mathrm{~h}$ at $39^{\circ} \mathrm{C}$, which were the optimum conditions obtained from previous work ${ }^{19}$. Upon completion, samples were rapidly cooled in an ice bath to stop further fermentation and stored at $2-4^{\circ} \mathrm{C}$ until further analysis.

\section{Determination of GABA Content}

GABA and glutamate were determined following the method previously described by ${ }^{11}$ using HPLC system (Shimadzu LC 20AT, Shimadzu Corporation, Kyoto, Japan) equipped with oven (model CT010ASVP), pump system and PDA detector (model SPD-M20A). Chromolith ${ }^{\circledR}$ RP-18 endcapped separation column (100 mm length $\times 4.6 \mathrm{~mm}$ internal diameter, Merck KGaA, Darmstadt, Germany) was used for this analysis. Yogurt sample was centrifuged at $10,000 \times \mathrm{g}$ for $15 \mathrm{~min}$ at $4^{\circ} \mathrm{C}$ and $10 \mu \mathrm{L}$ of the supernatant was placed into small durham tube and evaporated under vacuum for $40 \mathrm{~min}$. Then, the dried supernatant was dissolved in $20 \mu \mathrm{L}$ of a mixture of ethanol/water/triethylamine solution at a ratio of 2:2:1 and vacuum-evaporated for another $40 \mathrm{~min}$, followed by addition of $30 \mu \mathrm{L}$ of a mixture of ethanol/water/triethylamine/phenylisothiocyanate solution at a ratio of 7:1:1:1 and left for 20 min at room temperature to allow phenylisothiocyanate-GABA formation. The sample was vacuum-evaporated again for 40 min to remove excess reactant.

The derivatized sample was then diluted and subjected to HPLC analysis. Mobile phase A was prepared by dissolving $8.205 \mathrm{~g}$ of sodium acetate, $0.5 \mathrm{~mL}$ of trimethylamine and $0.7 \mathrm{~mL}$ of acetic acid in $1000 \mathrm{~mL}$ of deionized water, then the $\mathrm{pH}$ was adjusted to 5.8 using $0.1 \mathrm{M}$ sodium hydroxide. Meanwhile, mobile phase $B$ was prepared by mixing acetonitrile with deionized water at a ratio of $60: 40(\mathrm{v} / \mathrm{v})$. Both mobile phases were filtered through a $0.45 \mu \mathrm{m}$ membrane filter. Sample was injected at $5 \mu \mathrm{L}$ and eluted at a flow rate of $0.6 \mathrm{~mL} / \mathrm{min}$ using isocratic elution of $80 \%$ mobile phase $A+20 \%$ mobile phase $B$. Compound detection was performed using a diode array detector at $\lambda=254 \mathrm{~nm}$. The GABA and glutamate contents were calculated by comparing the sample peak area with GABA standard and glutamate standard, respectively.

\section{Viable Cell Count}

Bacterial enumeration was performed using the pour plate method. Firstly, $1.0 \mathrm{~g}$ gram of yogurt sample was diluted with $9.0 \mathrm{~mL}$ of sterile peptone water. Subsequently, a 10-fold dilution was made using peptone water, and $0.1 \mathrm{~mL}$ of the diluted sample was spread on MRS agar and cultured at $37 \otimes \mathrm{C}$ for $48 \mathrm{~h}$ to allow cell growth. The colonies appearing on the plates were then counted, multiplied by dilution factor, and expressed as log colony forming unit per $\mathrm{g}(\log \mathrm{CFU} / \mathrm{g})$. 


\section{Gastrointestinal Stability Study (Simulated Digestion)}

From six yogurt samples added with different sugars and probiotics, sample showing the highest GABA content and viable cell count was selected for further product performance evaluation and characterisation as follows: Gastrointestinal stability study, 28-days storage stability study and metabolomics profiling. Simulated digestion was performed following the method described by ${ }^{52}$. Two solutions were prepared, namely simulated-gastric-fluid (SGF) and simulated-intestinal-fluid (SIF). The SGF was prepared by mixing $20 \mathrm{mg} / \mathrm{mL}$ of pepsin, $350 \mu \mathrm{L}$ of concentrated $\mathrm{HCl}$ and $0.1 \mathrm{~g}$ of $\mathrm{NaCl}$ in deionized water to a total volume of $50 \mathrm{~mL}$ and the $\mathrm{pH}$ was adjusted to 1.2. Next, $1 \mathrm{~mL}$ of the SGF solution was added to $3 \mathrm{~mL}$ of yogurt and incubated at $37^{\circ} \mathrm{C}$ in water bath shaker for $2 \mathrm{~h}$. Meanwhile, SIF solution was prepared by mixing $34 \mathrm{mg} / \mathrm{mL}$ of $\mathrm{KH}_{2} \mathrm{PO}_{4}, 3.85 \mathrm{~mL}$ of $\mathrm{NaOH}(200 \mathrm{mM})$ and $0.5 \mathrm{~g}$ of pancreatin in deionized water to a final volume of $50 \mathrm{~mL}$ and the $\mathrm{pH}$ was adjusted to 6.8 . Then, $1 \mathrm{~mL}$ of the SIF solution was added to the reaction mixture and re-incubated for $4 \mathrm{~h}$ under the same condition. Aliquots of $1 \mathrm{~mL}$ were taken at $0,2,4$ and $6 \mathrm{~h}$ and boiled at 100®C for $10 \mathrm{~min}$ to inactivate enzymes and stored at $-20^{\circ} \mathrm{C}$ for GABA content. For viable cell count, aliquots of $1 \mathrm{~mL}$ were also taken at $0,2,4$ and $6 \mathrm{~h}$ and rapidly cooled before storing at $-20^{\circ} \mathrm{C}$.

\section{$\mathrm{pH}$ determination}

The $\mathrm{pH}$ value of yogurt samples was measured using a pH meter (model S20 SevenEasy ${ }^{\text {TM }}$, MettlerToledo $\mathrm{GmbH}$, Columbus, $\mathrm{OH}$, USA).

\section{Water holding capacity and syneresis}

The water-holding capacity (WHC) of yogurt was determined according to the modified procedure described by ${ }^{53}$. Yogurt sample of $10 \mathrm{~g}\left(\mathrm{~W}_{1}\right)$ was centrifuged at $5000 \mathrm{~g}$ for $10 \mathrm{~min}$ at $4^{\circ} \mathrm{C}$. The supernatant was collected and weighed $\left(\mathrm{W}_{2}\right)$. WHC (\%) was calculated as follows.

$\mathrm{WHC}=\mathrm{W}_{1}-\mathrm{W}_{2} / \mathrm{W}_{1} \times 100 \%$

Syneresis was determined according to the method from ${ }^{54}$. Briefly, $10 \mathrm{~g}$ of yogurt sample $\left(\mathrm{W}_{1}\right)$ was centrifuged at $700 \mathrm{~g}$ for $10 \mathrm{~min}$ at $4^{\circ} \mathrm{C}$. The supernatant was collected and weighed $\left(\mathrm{W}_{2}\right)$. Degree of syneresis (\%) was calculated as follows.

Degree of syneresis $=W_{2} / W_{1} \times 100$

\section{Metabolomics Profiling ('H-NMR Analysis)}

Yogurt samples were freeze dried and subjected to ${ }^{1} \mathrm{H}-\mathrm{NMR}$ analysis as described by ${ }^{55}$. A total of $10 \mathrm{mg}$ of freeze-dried yogurt was mixed with $0.375 \mathrm{~mL}$ of $\mathrm{CH}_{3} \mathrm{OH}-\mathrm{d}_{4}$ and $0.375 \mathrm{~mL}$ of $\mathrm{KH}_{2} \mathrm{PO}_{4}$ buffer in $\mathrm{D}_{2} \mathrm{O}$, containing $0.1 \%$ trimethylsilyl propionate as internal standard. The $\mathrm{pH}$ was adjusted to 6 with $\mathrm{NaOD}$. The mixture was vortexed for $1 \mathrm{~min}$, sonicated in an ultra-sonicator at 30खC for $15 \mathrm{~min}$ and centrifuged at 
$13,000 \mathrm{rpm}$ for $10 \mathrm{~min}$. Supernatant aliquot of $600 \mu \mathrm{L}$ was transferred to NMR tube for ${ }^{1} \mathrm{H}-\mathrm{NMR}$ analysis. Spectra were recorded at 26खC on a spectrometer (model UNITY INOVA 500, Agilent Technologies Inc., Santa Clara, CA, USA) using a frequency of $500 \mathrm{MHz}$. Tetramethylsilane was used as an internal standard. The spectra were automatically phased and bucketed with standard bins of $\delta 0.05$ ranging from region $\delta 0.50$ to 10.00 . The metabolites were identified using Chenomx software version 8.5 (Chenomx Inc., Edmonton, Canada). The residual methanol region ( $\delta 3.28$ to 3.33) and water region ( $\delta$ 4.70 to 4.96) were excluded from the analysis. Two-dimensional ${ }^{1} \mathrm{H}-{ }^{1} \mathrm{H} \mathrm{J}$-resolved and Heteronuclear Multiple-Bond Correlation (HMBC) were employed for the metabolites identification. Six replicates were examined for each yogurt sample.

\section{Statistical Analysis}

Analysis of variance (ANOVA) followed by Duncan's test and 2-sample t-test were used to evaluate means at significant difference of $\mathrm{p}<0.05$ using Minitab software version 16 (Minitab Inc., State College, PA, USA). All values were reported as means \pm standard deviation from at least triplicate determinations.

\section{Declarations}

\section{Acknowledgement}

This work was conducted following approval by National Board of Biosafety, under the Ministry of Natural Resources and Environment, Malaysia [JBK (S) 602-1/2/207] and supported by the PUTRA grant scheme under the project GP-IPS/2016/No. 9493300 from Universiti Putra Malaysia (UPM), Malaysia.

\section{Author contributions}

F.S.H. performed data curation, formal analysis, investigation, methodology, writing original draft, S.Y.C performed review and editing, M.S.A.G performed preliminary experiments, A.S.M.H. and W.Z.W.I. supervised and contribute resources, B.J.M. performed NMR data curation and N.S. designed concept with supervision, reviewing and editing, and funding acquisition. All authors have read and agreed to the final version of the manuscript.

\section{Conflict of interest}

All authors declare no conflicts of interest.

\section{References}

1. Savaiano. Lactose digestion from yogurt: mechanism and relevance. The American journal of clinical nutrition, 99, 1251S-1255S. https://doi.org/10.3945/ajcn.113.073023.1 (2014).

2. Linares, D. M., O'Callaghan, T. F., O'Connor, P. M., Ross, R. P. \& Stanton, C. Streptococcus thermophilus APC151 strain is suitable for the manufacture of naturally GABA-enriched bioactive yogurt. Front. 
Microbiol. 7, 1876. https://doi.org/10.3389/fmicb.2016.01876 (2016).

3. Hong, Y. F. et al. Immune regulatory effect of newly isolated Lactobacillus delbrueckii from Indian traditional yogurt. J. Microbiol. Biotechnol. 25, 1321-1323. https://doi.org/10.4014/jmb.1501.01057 (2015).

4. Mordor-Intelligence. Yogurt market-growth, trends and forecasts (2019-2024). https://www.mordorintelligence.com/industry-reports/yogurt-market

5. Gomaa, E. Z. Enhancement of $y$-aminobutyric acid production by co-culturing of two Lactobacilli strains. Asian J. Biotechnol. 7, 108-118. https://doi.org/10.3923/ajbkr.2015.108.118 (2015).

6. Nishimura, M. et al. Effects of white rice containing enriched gamma-aminobutyric acid on blood pressure. J. Tradit. Complement. Med. 6, 66-71. https://doi.org/10.1016/j.jtcme.2014.11.022 (2016).

7. Kim, N. Y. \& Ji, G. E. Characterization of the production of biogenic amines and gamma-aminobutyric acid in the soybean pastes fermented by Aspergillus oryzae and Lactobacillus brevis. J. Microbiol. Biotechnol. 25, 464-468. https://doi.org/10.4014/jmb.1409.09081(2015).

8. Yoshimura, M. et al. Antihypertensive effect of a $y$-aminobutyric acid rich tomato cultivar 'DG03-9' in spontaneously hypertensive rats. J. Agric. Food Chem. 58, 615-619. https://doi.org/10.1021/jf903008t (2010).

9. Soltani, N. et al. GABA exerts protective and regenerative effects on islet beta cells and reverses diabetes. Proc. Natl. Acad. Sci. U. S. A. 108, 11692-11697 https://doi.org/10.1073/pnas.1102715108 (2011).

10. Ohmori, T., Tahara, M. \& Ohshima, T. Mechanism of gamma-aminobutyric acid (GABA) production by a lactic acid bacterium in yogurt-sake. Process Biochem. 74, 21-27 https://doi.org/10.1016/j.procbio.2018.08.030 (2018).

11. Tajabadi, N. et al. Overexpression and optimization of glutamate decarboxylase in Lactobacillus plantarum Taj-Apis362 for high gamma-aminobutyric acid production. Microb. Biotechnol. 8, 623632. https://doi.org/10.1111/1751-7915.12254 (2015).

12. Directive, C. Council Directive 90/219/EEC of 23 April 1990 on the contained use of genetically modified micro-organisms. Official Journal L, 117:08, 5 (1990).

13. Gaspar, P., Carvalho, A. L., Vinga, S., Santos, H. \& Neves, A. R. From physiology to systems metabolic engineering for the production of biochemicals by lactic acid bacteria. Biotechnol. Adv. 31, 764-788. https://doi.org/10.1016/j.biotechadv.2013.03.011 (2013).

14. Nejati, F. et al. Manufacture of a functional fermented milk enriched of Angiotensin-I Converting Enzyme (ACE) -inhibitory peptides and gamma -amino butyric acid (GABA). LWT - Food Sci. Technol. 51, 183-189 https://doi.org/10.1016/j.Iwt.2012.09.017 (2013).

15. Hasegawa, M., Yamane, D., Funato, K., Yoshida, A. \& Sambongi, Y. Gamma-aminobutyric acid fermentation with date residue by a lactic acid bacterium, Lactobacillus brevis. J. Biosci. Bioeng. 125, 316-319. https://doi.org/10.1016/j.jbiosc.2017.10.003 (2018).

16. Anggraini, L., Marlida, Y., Wizna, W., Jamsari, J. \& Mirzah, M. Optimization of nutrient medium for Pediococcus acidilactici DS15 to produce GABA. J. World's Poult. Res. 9, 139-146. 
https://doi.org/10.36380/jwpr.2019.17 (2019).

17. Binh, T. T. T., Ju, W. T., Jung, W. J. \& Park, R. D. Optimization of $y$-amino butyric acid production in a newly isolated Lactobacillus brevis. Biotechnol. Lett. 36, 93-98 (2014).

18. Shan, Y. et al. Evaluation of improved gamma aminobutyric acid production in yogurt using Lactobacillus plantarum NDC75017. 2138-2149 (2015). doi:10.3168/jds.2014-8698

19. Hussin, F. S. et al. Potentiality of self-cloned Lactobacillus plantarum Taj-Apis362 for enhancing GABA production in yogurt under glucose Induction: Optimization and its cardiovascular effect on spontaneous hypertensive rats. Foods 9, 1826. https://doi:10.3390/foods912182 (2020).

20. Li, X. et al. Molecular mechanisms of furanone production through the EMP and PP pathways in Zygosaccharomyces rouxii with D-fructose addition. Food Res. Int. 133, 109137 (2020).

21. Shan, Y., Yong, L. \& Aixin, Y. Metabolic reprogramming under microaerobic and anaerobic conditions in bacteria. In Reprogramming microbial metabolic pathways, 159-179. Springer, Dordrecht. https://doi.org/10.1007/978-94-007-5055-5 (2012).

22. Lopes, S. M. S. et al. Isolation and characterization of inulin with a high degree of polymerization from roots of Stevia rebaudiana (Bert.) bertoni. Carbohydr. Res. 411, 15-21. https://doi.org/10.1016/j.carres.2015.03.018 (2015).

23. Hernandez-Hernandez, O. et al. Effect of prebiotic carbohydrates on the growth and tolerance of Lactobacillus. Food Microbiol. 30, 355-361. https://doi.org/10.1016/j.fm.2011.12.022 (2012).

24. Rayes, A. Enhancement of probiotic bioactivity by some prebiotics to produce bio-fermented milk. Life Science Journal, 9, 2246-2253 (2012).

25. Van Arkel, J. et al. Tailor-made fructan synthesis in plants: A review. Carbohydr. Polym. 93, 48-56 https://doi.org/10.1016/j.carbpol.2012.02.001 (2013).

26. Choudhary, S. et al. Principal component analysis of stimulatory effect of synbiotic combination of indigenous probiotic and inulin on antioxidant activity of soymilk. Probiotics Antimicrob. Proteins 11, 813-819. https://doi.org/10.1007/s12602-018-9432-9 (2019).

27. Sarbini, S. R. \& Rastall, R. A. Prebiotics: Metabolism, Structure, and Function. 3, 93-106. https://doi.org/10.2310/6180.2011.00004 (2011).

28. Mandadzhieva, T., Ignatova-Ivanova, T., Kambarev, S., Iliev, I. \& Ivanova, I. Utilization of different prebiotics by Lactobacillus spp. and Lactococcus spp. Biotechnol. Biotechnol. Equip. 25, 117-120 https://doi.org/10.5504/bbeq.2011.0132 (2011).

29. Yi, H. \& Chui, R. Optimization of culture conditions for gamma-aminobutyric acid production in fermented adzuki bean milk. J. Food Drug Anal. 26, 74-81 https://doi.org/10.1016/j.jfda.2016.11.024 (2017).

30. Li, H., Qiu, T., Huang, G. \& Cao, Y. Production of gamma-aminobutyric acid by Lactobacillus brevis NCL912 using fed-batch fermentation. Microb. Cell Fact. 9, 85. https://doi.org/10.1186/1475-2859-985 (2010). 
31. Le, P. H., Le, T. T. \& Raes, K. Effects of $\mathrm{pH}$ and heat treatment on the stability of Y-aminobutyric acid (GABA) in germinated soymilk. J. Food Process. Preserv. 44, 1-7. https://doi.org/10.1111/jfpp.14301 (2020).

32. Bedani, R., Rossi, E. A. \& Saad, S. M. I. Impact of inulin and okara on Lactobacillus acidophilus La-5 and Bifidobacterium animalis Bb-12 viability in a fermented soy product and probiotic survival under in vitro simulated gastrointestinal conditions. Food Microbiol. 34, 382-389. https://doi.org/10.1016/j.fm.2013.01.012 (2013).

33. Silva, P. D. L. da, Bezerra, M. de F., Santos, K. M. O. dos \& Correia, R. T. P. Potentially probiotic ice cream from goat's milk: Characterization and cell viability during processing, storage and simulated gastrointestinal conditions. LWT - Food Sci. Technol. 62, 452-457 https://doi.org/10.1016/j.lwt.2014.02.055 (2015).

34. Sanchart, C., Rattanaporn, O., Haltrich, D., Phukpattaranont, P. \& Maneerat, S. Technological and safety properties of newly isolated GABA-producing Lactobacillus futsaii strains. J. Appl. Microbiol. 121, 734-745. https://doi.org/10.1111/jam.13168 (2016).

35. Wang, H. K., Dong, C., Chen, Y. F., Cui, L. M. \& Zhang, H. P. A new probiotic Cheddar cheese with high ACE-inhibitory activity and $Y$-aminobutyric acid content produced with koumiss-derived Lactobacillus casei Zhang. Food Technol. Biotechnol. 48, 62-70 (2010).

36. Abd El-Fattah, A., Sakr, S., El-Dieb, S. \& Elkashef, H. Developing functional yogurt rich in bioactive peptides and gamma-aminobutyric acid related to cardiovascular health. Lwt 98, 390-397. https://doi.org/10.1016/j.lwt.2018.09.022 (2018).

37. Shiby, V. K. \& Mishra, H. N. Fermented milks and milk products as functional foods-A Review. Crit. Rev. Food Sci. Nutr. 53, 482-496. https://doi.org/10.1080/10408398.2010.547398 (2013).

38. Hussein, S. A. Probiotic stability of yoghurts during refrigerated storage. Egyptian Academic Journal of Biological Sciences, G. Microbiology, 5, 9-19 (2013).

39. Li, H. \& Cao, Y. Lactic acid bacterial cell factories for gamma-aminobutyric acid. Amino Acids 39, 1107-1116. https://doi.org/10.1007/s00726-010-0582-7 (2010).

40. Watanabe, Y. Effects of co-culturing LAB on GABA production. Journal of Biological Macromolecules, 11, 3-13. doi:10.1021/acsreagents.4062.20160601 (2011).

41. Akalin, A. S., Unal, G., Dinkci, N. \& Hayaloglu, A. A. Microstructural, textural, and sensory characteristics of probiotic yogurts fortified with sodium calcium caseinate or whey protein concentrate. J. Dairy Sci. 95, 3617-3628. https://doi.org/10.3168/jds.2011-5297 (2012).

42. Cakmakci, S., Tahmas-Kahyaoglu, D., Erkaya, T., Cebi, K. \& Hayaloglu, A. A. $\beta$-Carotene contents and quality properties of set type yoghurt supplemented with carrot juice and sugar. J. Food Process. Preserv. 38, 1155-1163. https://doi.org/10.1111/jfpp.12075 (2014).

43. Lobato-Calleros, C., Ramírez-Santiago, C., Vernon-Carter, E. J. \& Alvarez-Ramirez, J. Impact of native and chemically modified starches addition as fat replacers in the viscoelasticity of reduced-fat stirred yogurt. J. Food Eng. 131, 110-115. https://doi.org/10.1016/j.jfoodeng.2014.01.019 (2014). 
44. Nguyen, H. T. H., Ong, L., Kentish, S. E. \& Gras, S. L. The Effect of fermentation temperature on the microstructure, physicochemical and rheological properties of probiotic buffalo yoghurt. Food Bioprocess Technol. 7, 2538-2548. https://doi.org/10.1007/s11947-014-1278-x (2014).

45. Kim, H. K., Choi, Y. H. \& Verpoorte, R. NMR-based metabolomic analysis of plants. Nat. Protoc. 5, 536-549. https://doi.org/10.1038/nprot.2009.237 (2010).

46. Park, S. E. et al. GC-MS based metabolomics approach of Kimchi for the understanding of Lactobacillus plantarum fermentation characteristics. LWT - Food Sci. Technol. 68, 313-321. https://doi.org/10.1016/j.Iwt.2015.12.046 (2016).

47. Hole, A. S. et al. Improved bioavailability of dietary phenolic acids in whole grain. J. Agric. Food Chem. 60, 6369-6375. https://doi.org/doi.org/10.1021/jf300410h (2012).

48. Sørensen, K. I., Curic-bawden, M., Junge, M. P. \& Janzen, T. Enhancing the sweetness of yoghurt through metabolic remodeling of carbohydrate metabolism in Streptococcus thermophilus and Lactobacillus delbrueckii subsp. bulgaricus. 82, 3683-3692. https://doi.org/10.1128/AEM.0046216.Editor (2016).

49. Zhang, S. S., Xu, Z. S., Qin, L. H. \& Kong, J. Low-sugar yogurt making by the co-cultivation of Lactobacillus plantarum WCFS1 with yogurt starter cultures. J. Dairy Sci. https://doi.org/10.3168/jds.2019-17347 (2020).

50. Chen, C. et al. Role of lactic acid bacteria on the yogurt flavour: A review. Int. J. Food Prop. 20, S316S330. https://doi.org/10.1080/10942912.2017.1295988 (2017).

51. Steele, J., Broadbent, J. \& Kok, J. Perspectives on the contribution of lactic acid bacteria to cheese flavor development. Curr. Opin. Biotechnol. 24, 135-141. https://doi.org/10.1016/j.copbio.2012.12.001 (2013).

52. Auwal, S. M., Zarei, M., Tan, C. P., Basri, M. \& Saari, N. Enhanced physicochemical stability and efficacy of angiotensin I-converting enzyme (ACE) - Inhibitory biopeptides by chitosan nanoparticles optimized using Box-Behnken design. Sci. Rep. 8, 1-12. https://doi.org/10.1038/s41598-018-286595 (2018).

53. Abdelmoneim, A. H., Sherif, A. M. \& Sameh, K. A. Rheological properties of yoghurt manufactured by using different types of hydrocolloids. Austin J. Nutr. Food Sci. 4, 1-6 (2016).

54. Aguilera J. M., \& Kessler, H. -G. Properties of mixed and filled-type dairy Gels. J. Food Sci. 54, 12131217. https://doi.org/10.1111/j.1365-2621.1989.tb05957.x (1989).

55. Muhialdin, B. J., Kadum, H., Zarei, M. \& Meor Hussin, A. S. Effects of metabolite changes during lacto-fermentation on the biological activity and consumer acceptability for dragon fruit juice. Lwt 121, 108992 https://doi.org/10.1016/j.Iwt.2019.108992 (2020).

\section{Tables}


Table 1

Metabolite profiles in freeze-dried GABA-rich yogurt (GY) and freeze-dried standard yogurt (SY) determined using ${ }^{1} \mathrm{H}$-NMR metabolomics-based analysis.

\begin{tabular}{|c|c|c|c|}
\hline Metabolite & ${ }^{1}$ H-NMR Characteristic Signals & GY & SY \\
\hline & & \multicolumn{2}{|c|}{$\mathrm{mg} / 100 \mathrm{~g}$} \\
\hline Glucose & $\delta 3.889$ (dd), $\delta 3.824$ (m), $\delta 3.889$ (dd) & 311.85 & 226.64 \\
\hline Glutamate & $\delta 2.04(\mathrm{~m}), \delta 2.119(\mathrm{~m}), \delta 2.341(\mathrm{~m}), \delta 3.748(\mathrm{dd})$ & 461.25 & ND \\
\hline GABA & $\delta 1.89(\mathrm{~m}), \delta 2.28(\mathrm{t}), \delta 3.00(\mathrm{t})$ & 97.65 & 25.10 \\
\hline Glutamine & $\delta 2.13(\mathrm{~m}), \delta 2.44(\mathrm{~m})$ & 290.53 & ND \\
\hline Alanine & $\delta 1.47(d)$ & 15.45 & 18.97 \\
\hline Histidine & $\delta 3.16(\mathrm{dd}), \delta 3.23(\mathrm{dd})$ & 205.49 & 152.98 \\
\hline Choline & $\delta 3.189(\mathrm{~s})$ & ND & 29.48 \\
\hline Proline & $\delta 3.33(\mathrm{dt}), \delta 3.34(\mathrm{~m})$ & 54.34 & ND \\
\hline Cysteine & $\delta 3.38(\mathrm{dd})$ & 177.02 & ND \\
\hline Valine & $\delta 3.61$ (d), 3.7 (m), & 38.80 & 14.41 \\
\hline \multirow[t]{2}{*}{ Lactose } & $\delta 3.55(\mathrm{~m}), \delta 3.79(\mathrm{~m}), \delta 4.44(\mathrm{~d})$ & \multirow[t]{2}{*}{346.41} & \multirow[t]{2}{*}{1025.00} \\
\hline & $\delta 5.22(d)$ & & \\
\hline Lactulose & 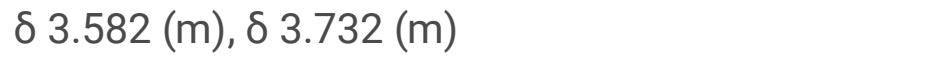 & 189.54 & 307.23 \\
\hline Trehalose & $\delta 3.44(\mathrm{t}), \delta 5.18(\mathrm{~d})$ & 1174.00 & 842.39 \\
\hline Arabinose & $\delta 3.68(\mathrm{~m}), \delta 3.95(\mathrm{~m}), \delta 4.52(\mathrm{~d})$ & 196.37 & 367.82 \\
\hline Galactose & $\delta 4.07(\mathrm{t})$ & 549.48 & 441.38 \\
\hline N-Acetylglucosamine & $\delta 3.47(\mathrm{~m}), \delta 3.65(\mathrm{dd}), \delta 3.76(\mathrm{~m})$ & 51.10 & 49.55 \\
\hline Lactic acid & $\delta 1.32(\mathrm{~d}), \delta 4.14(\mathrm{~d})$ & 1338.00 & 2060.00 \\
\hline
\end{tabular}

\section{Figures}


A)

GABA
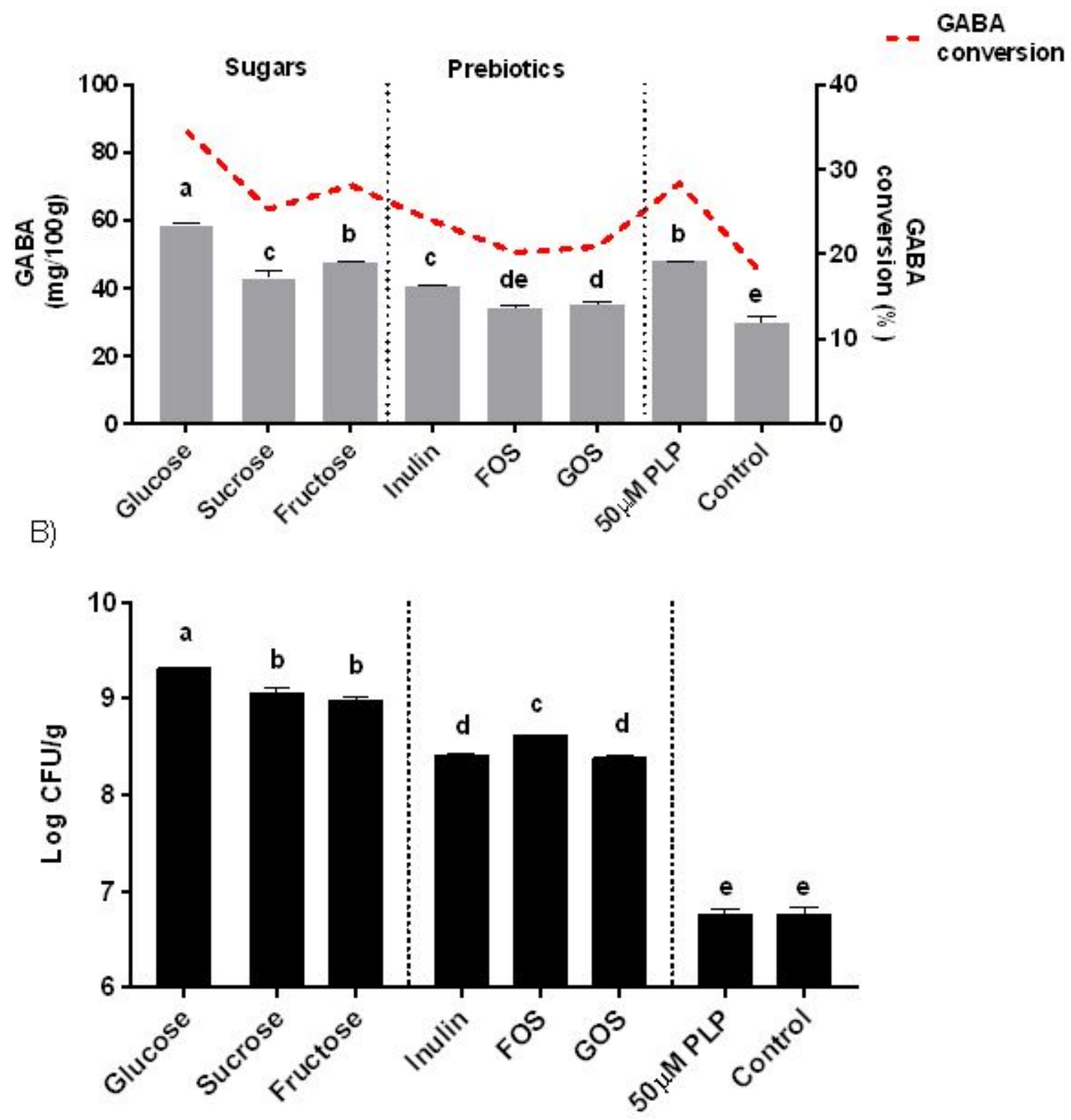

Types of carbohy drates

Figure 1

Effect of simple carbohydrates on (A) GABA content and conversion rate and (B) Viable cell count in yogurt. Different letters indicate significant difference at $p<0.05$. 


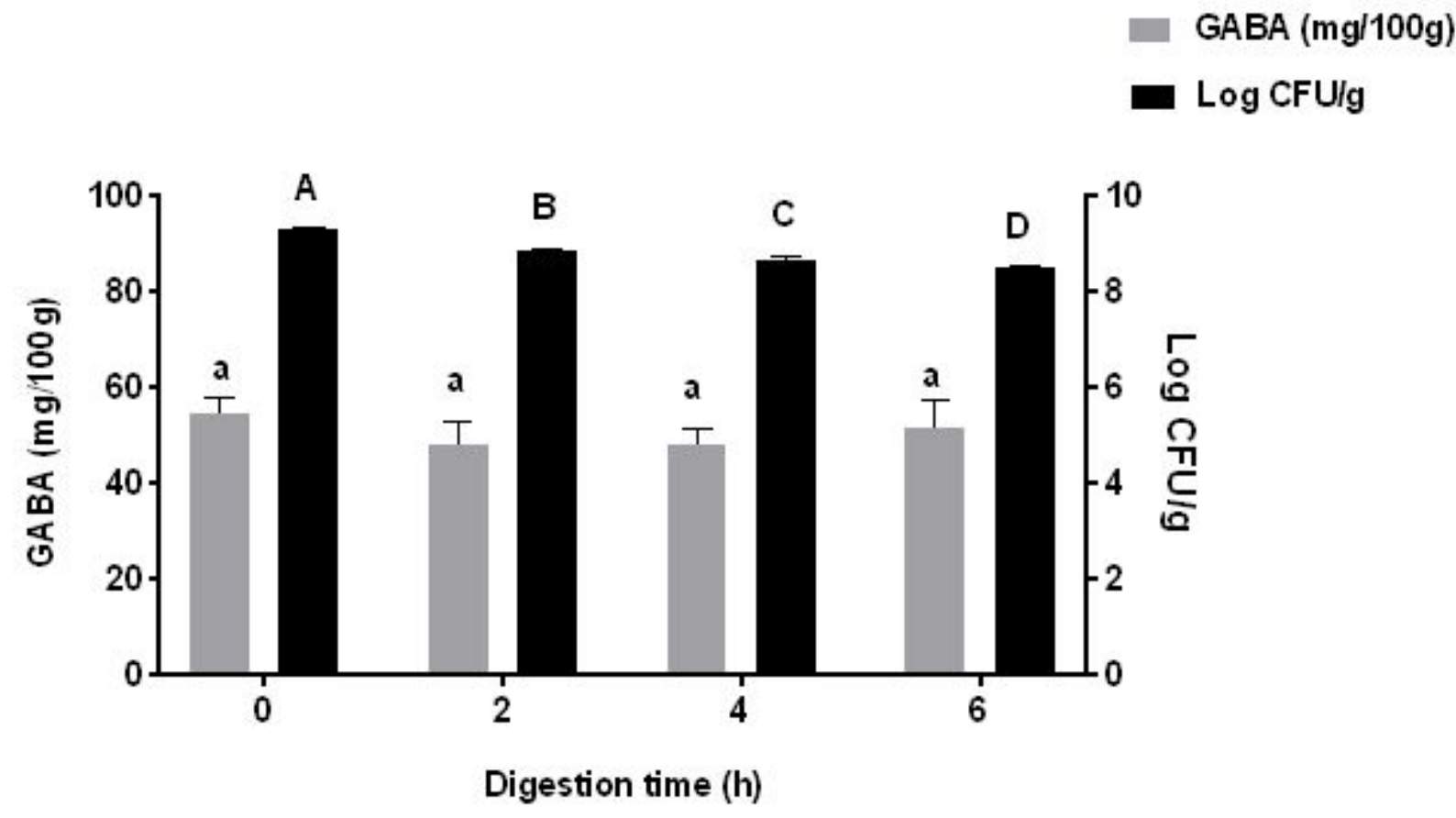

Figure 2

Effect of simulated digestion on GABA content and viable cell count in GABA-rich yogurt. Different letters indicate significant difference $(p<0.05)$ for GABA content (capital letters) and viable cell count (small letters) during $6 \mathrm{~h}$ of simulated digestion. 


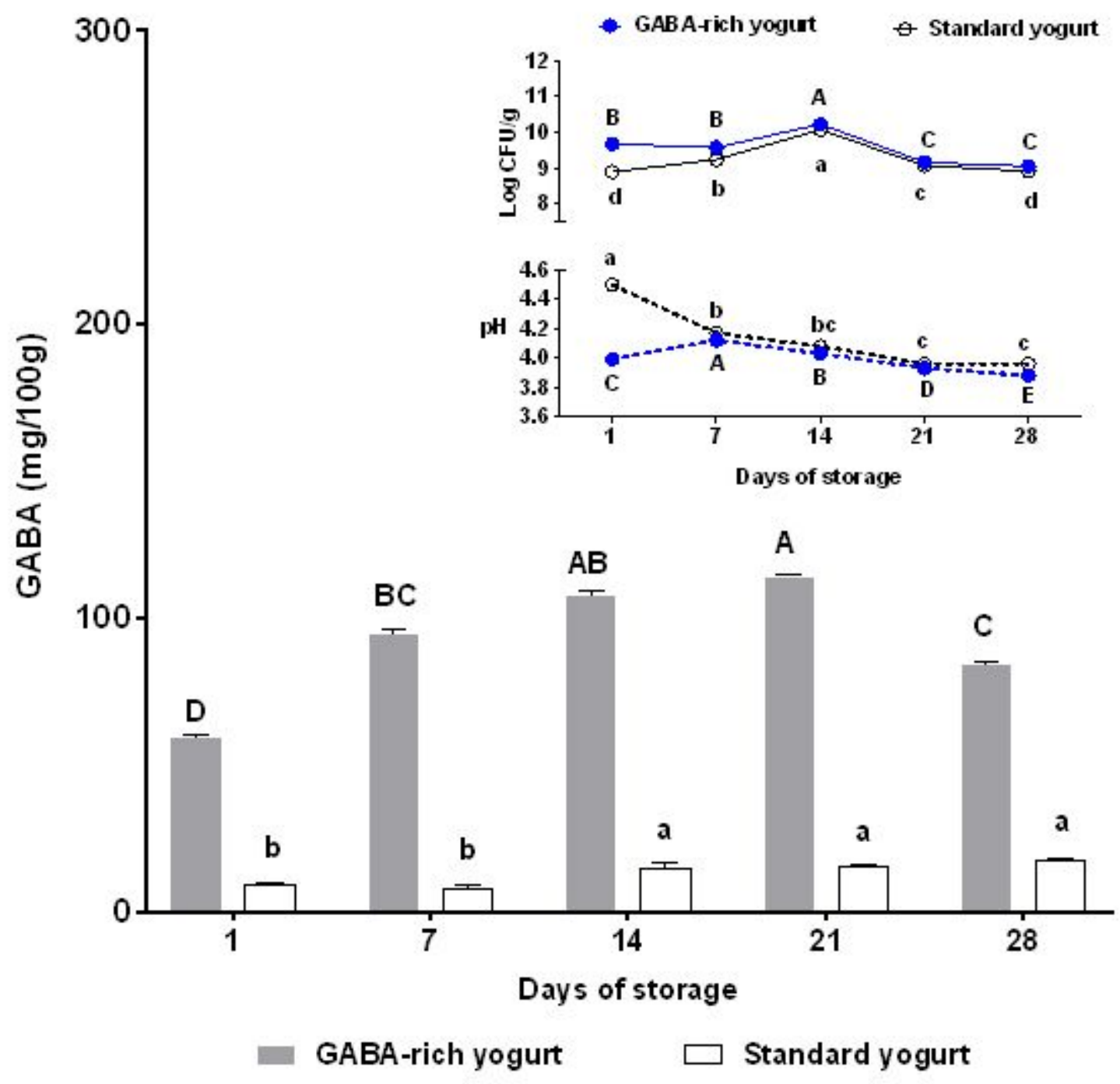

Figure 3

GABA content, viable cell count and pH of GABA-rich yogurt compared to standard yogurt during 28 days of storage at $4 \bowtie C$. Different letters indicate significant difference $(p<0.05)$ among GABA-rich yogurt (capital letters) and standard yogurt (small letters) on different days of storage. 


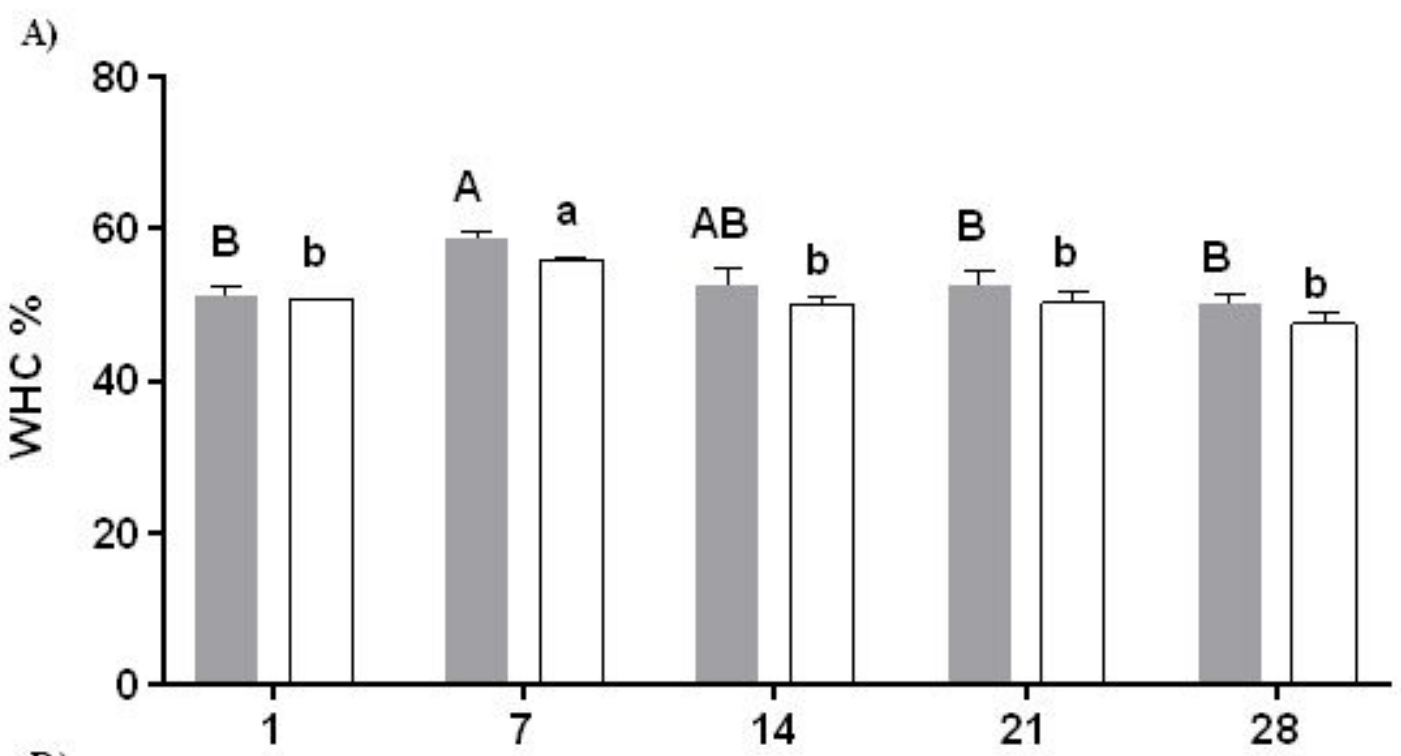

B)

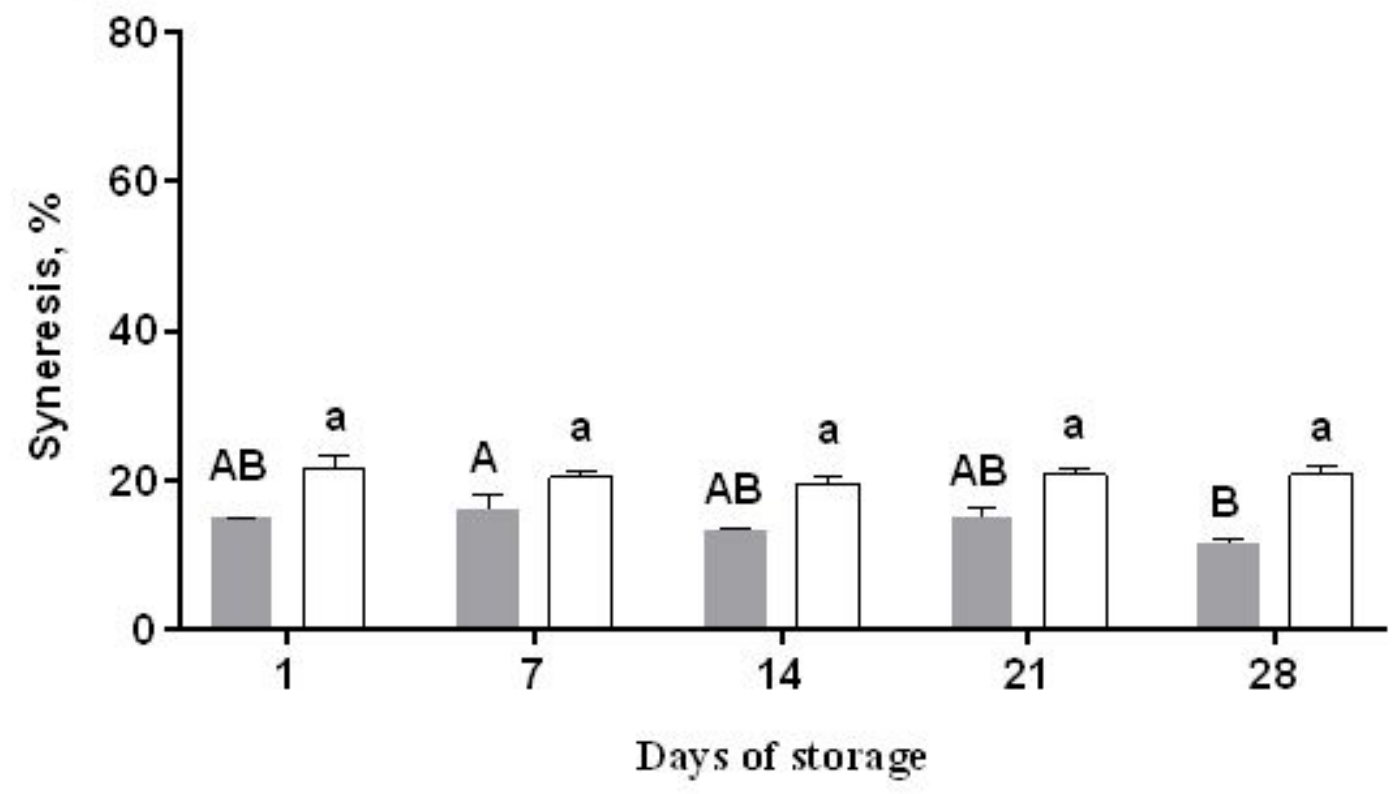

Figure 4

Effect of refrigerated storage on (A) WHC and (B) syneresis of GABA-rich yogurt compared to standard yogurt. Different letters indicate significant difference $(p<0.05)$ for GABA-rich yogurt (capital letters) and standard yogurt (small letters) on different days of storage. 


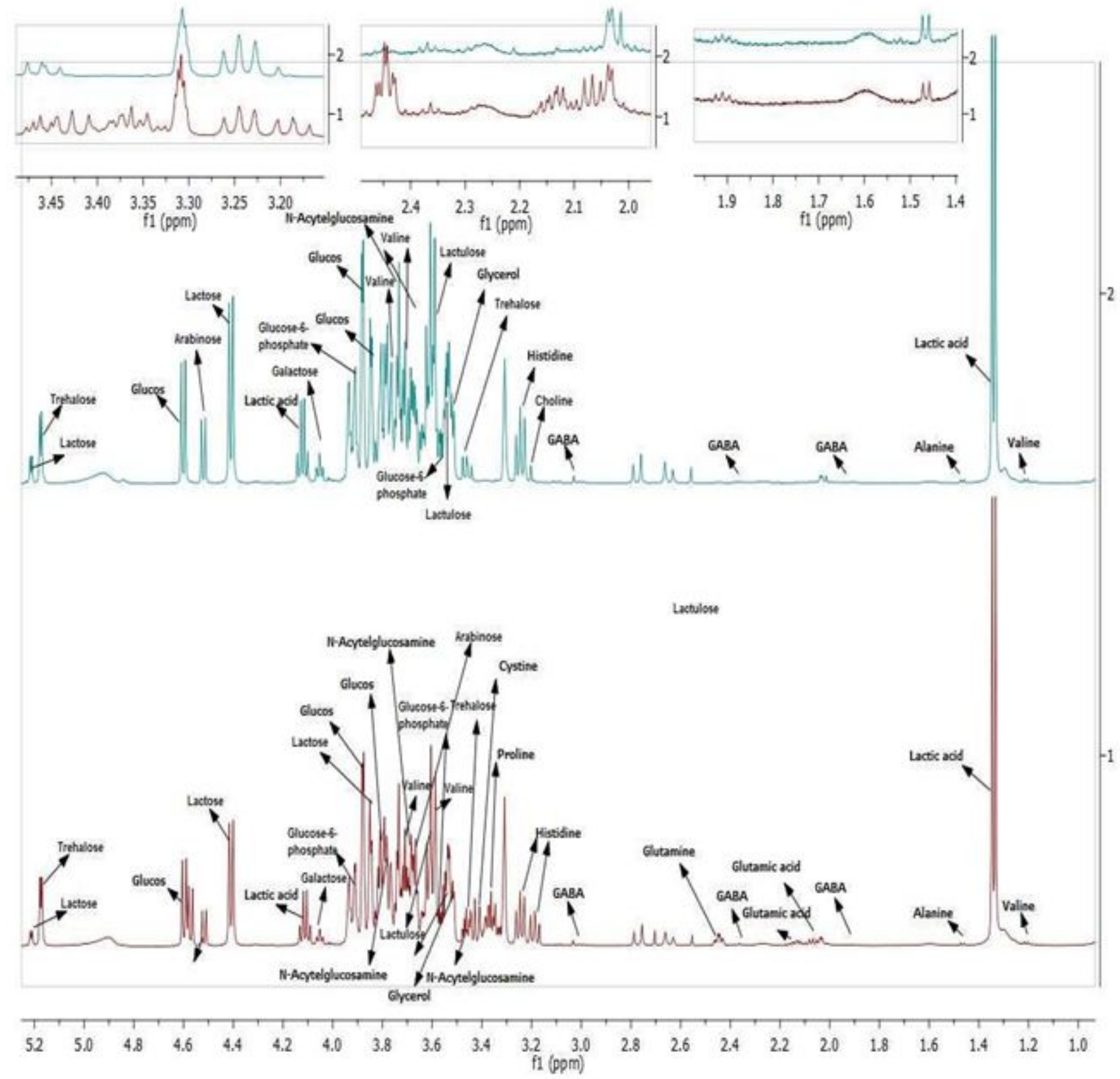

Figure 5

1H-NMR spectra of (A) freeze-dried standard yogurt (SY) and (B) freeze-dried GABA-rich yogurt (GY). 